\title{
Cuando la protesta importa electoralmente. El perfil sociodemográfico y político de los manifestantes contra la guerra de Irak
}

\author{
Manuel Jiménez
}

Universidad Pablo de Olavide de Sevilla

mjimsan@upo.es

\section{Resumen}

Este trabajo analiza el perfil sociodemográfico y las actitudes y los comportamientos políticos de los participantes en la manifestación contra la guerra de Irak del 15 de febrero de 2003. El objetivo de este análisis es responder a tres preguntas: ¿quién se manifestó? ¿cuáles fueron las motivaciones para hacerlo? y ¿cuáles fueron las implicaciones electorales de la cuestión de Irak desde la perspectiva de los manifestantes? La respuesta a estas preguntas se inserta en las explicaciones sobre la normalización de la actividad de protesta en las democracias representativas y sus implicaciones en términos electorales que señalan la existencia de un cambio hacia la individualización de la política, reflejado, entre otros síntomas, en el debilitamiento de los anclajes partidistas del voto y la importancia del llamado «voto temático».

Palabras clave: participación no convencional, protesta social, guerra de Irak, voto temático, elecciones generales de 2004.

Abstract. When protest matters electorally. The sociodemographic and political profile of demonstrators against the Iraq war

This paper analyses the socio-demographic profile and the political attitudes and behaviours of participants in the $15^{\text {th }}$ of February of 2003 demonstration against the Iraq war. We aim to respond to three questions: who demonstrated? ¿which were the motivations for doing so? and ¿which were the electoral implications of the Iraq issue from the perspective of demonstrators? Our answers to these questions are framed within those explanations of the normalization of protest activity in representative democracies and its implications in electoral terms that point out to the existence of a shift towards an individualization of politics, reflected in, among other symptoms, the weakening of party anchored voting and increasing relevance of issue voting.

Key words: non-conventional participation, social protest, Iraq war, issue voting, Spanish general elections 2004. 


\section{Sumario}

Introducción Perfil conductual de los participantes

Enfoque analítico y relevancia teórica Los datos: la encuesta IPPS en España

La movilización contra la guerra y el perfil político de los participantes

Rasgos sociodemográficos de los participantes del 15-F

Perfil actitudinal de los participantes en el 15-F

A modo de síntesis

Motivaciones para manifestarse contra la guerra

Conclusiones: implicaciones electorales del 15-F

Bibliografia

\section{Introducción $^{1}$}

Las manifestaciones contra la guerra del 15 de febrero de 2003 (15-F) supusieron, por lo que sabemos, el evento de protesta de carácter internacional más grande jamás registrado en la historia hasta el momento. Se celebraron manifestaciones en más de 600 ciudades de 60 países diferentes, en las que, de acuerdo con las diferentes estimaciones recogidas en los medios de comunicación, participaron entre 10 y 30 millones de personas ${ }^{2}$. Esta jornada internacional contra la guerra marcó un momento álgido de una oleada de movilizaciones por la paz sin precedentes desde las protestas contra la guerra del Vietnam.

La movilización fue fruto de un único llamamiento global ${ }^{3}$, que desencadenó la constitución de diversas plataformas y redes de ámbito nacional compuestas por organizaciones vinculadas al movimiento de justicia global, organizaciones pacifistas y de otros movimientos sociales. Los intensos contactos entre estas redes produjeron una unificación de los mensajes y eslóganes que se escucharían en los diversos puntos del planeta en los que se celebraron actos de protesta («No en nuestro nombre», «No más sangre por petróleo», etc.). Esta dimensión organizativa confiere a la jornada de protesta un carácter transnacional sin precedentes en este tipo de movilizaciones.

En cada país, las plataformas convocantes establecieron alianzas con distintos actores de su entorno social y político. Así, en Madrid, la convocatoria corrió a cargo del Foro Social de Madrid (integrado por organizaciones sindicales, pacifistas, ecologistas, de solidaridad con países en desarrollo, ONG de desarrollo, partidos de izquierda, etc.), y contó con el apoyo, entre otros, del PSOE, de IU y de los sindicatos mayoritarios. La adhesión del PSOE y de un nutrido conjunto de actores y otras personalidades del mundo de la cultura

1. Agradezco los comentarios de los evaluadores anónimos de esta revista.

2. Walgrave y Verhust 2003; Chrisafis y otros, 2003; Graebner, 2003.

3. La iniciativa se planteó durante la celebración del Foro Social Europeo de Florencia, en noviembre de 2002, siendo asumida en enero de 2003 por el Foro Social Mundial de Porto Alegre 
(organizados en torno a la Plataforma Cultura contra la Guerra) elevó, en los días previos a la manifestación, las expectativas de participación de los organizadores hasta 100.000 personas. Estimaciones que se verían ampliamente superadas con la presencia de 660.000 personas (1 millón según los participantes), por lo que constituyó una de las manifestaciones más grandes jamás celebrada a favor de la paz ${ }^{4}$.

Este trabajo es fruto de una investigación más amplia, denominada International Peace Protest Survey (IPPS), en el marco de la cual se llevó a cabo una encuesta durante la celebración de las principales manifestaciones en siete países europeos (Reino Unido, Alemania, España, Italia, Suiza, Holanda y Bélgica) y en Estados Unidos. Sin negar el carácter transnacional de la movilización, los resultados preliminares de tipo comparado señalan la influencia del contexto político (y organizativo) doméstico, tanto en el volumen de participantes como en sus rasgos sociopolíticos y sus motivaciones para salir a las calles. En concreto, en los países en los que los gobiernos mantenían una clara posición a favor de la intervención, las movilizaciones fueron más concurridas (como Reino Unido, Italia o España, véase la tabla A.1 del anexo). En estos países, junto a los sentimientos y opiniones contrarias a la guerra, el componente de crítica a la actuación de los gobiernos fue un factor trascendente de movilización. En este sentido, en el caso de España, no se puede entender el carácter multitudinario de la jornada de protesta sin considerar la visibilidad mediática que confieren a la convocatoria el apoyo del PSOE y de personalidades del mundo de la cultura. La dimensión de oposición al Gobierno (cuyos representantes lanzan a sus seguidores un mensaje contrario a la participación en la manifestación indicando el carácter de oportunismo político de la oposición) actuó como un desincentivo para que los amplios sectores de votantes del PP opuestos a la guerra se sumaran a la manifestación. No obstante, como se muestra más adelante, un sector relativamente amplio de éstos optaría por participar en la jornada contra la guerra. Podemos pensar que su posición moral superó el desincentivo que plantea la lealtad al Gobierno del partido por el que votaron. Del mismo modo, la naturaleza de reprobación al Gobierno actuó como un incentivo (adicional) para la movilización de sectores más o menos vinculados electoralmente al PSOE y a IU. En este sentido, las protestas contra la guerra de Irak se insertan dentro de un ciclo creciente de movilización doméstica (con referentes en las movilizaciones contra las reformas educativas, la reforma laboral, el trasvase del Ebro, la presidencia de la UE, el Prestige, etc. $)^{5}$.

4. En España, se celebraron al menos 26 manifestaciones, sólo las seis más multitudinarias reunieron a 1,5 millones de personas, de acuerdo con las estimaciones policiales (El País, 16 de febrero 2003). De acuerdo con el barómetro del CIS de abril de 2003, un 25\% de los españoles (mayores de 16 años) habían participado en algún acto de protesta contra la intervención militar.

5. De cuerdo con una encuesta postelectoral de 2004 (Demoscopia, Estudio n. ${ }^{\circ}$ 174005), un $20 \%$ de los españoles había participado en alguna manifestación, incluidas las realizadas en protesta por la invasión de Irak. Con una muestra representativa de 2.929 españoles mayores de edad, la encuesta fue financiada por un consorcio de investigadores dirigidos 
Desde este planteamiento inicial, este trabajo analiza los distintos perfiles políticos de los manifestantes en Madrid (España) y sus distintas motivaciones para movilizarse. En primer lugar, se divide a los manifestantes en distintos grupos, de acuerdo con el comportamiento electoral pasado, para, en segundo lugar, trazar su perfil sociodemográfico y político. En tercer lugar, se analizan las motivaciones aducidas para participar en la manifestación y la opinión respecto a la actuación que debería seguir el Gobierno respecto a la entonces inminente invasión de Irak. Por último, a partir del análisis del cambio en las orientaciones del voto de los participantes, se evalúa el impacto potencial del tema de la guerra de Irak en las elecciones de marzo de 2004.

\section{Enfoque analítico y relevancia teórica}

El trabajo adopta un enfoque empírico fundamentalmente descriptivo desde una perspectiva teórica doble. Por un lado, el examen de los datos se inserta dentro de los enfoques analíticos de la participación política y, en concreto, de las teorías de la participación no convencional de tipo psicosocial, que enfatizan la influencia de los recursos personales (especialmente los cognitivos), las actitudes y el contexto institucional a la hora de explicar las pautas de acción de los individuos (Verba y otros, 1978) ${ }^{6}$. Los estudios más recientes dentro de esta línea de investigación señalan la existencia de tendencias de transformación en las actitudes y en los comportamientos políticos de los ciudadanos en las sociedades democráticas ${ }^{7}$. El descenso de la afiliación partidista y el aumento de la pertenencia a organizaciones sociales, el proceso de desalineamiento electoral $^{8}$ o la extensión del repertorio de la participación (a las formas no convencionales), serían algunas de las manifestaciones empíricas de este proceso

por Richard Gunther, José Ramón Montero y Mariano Torcal, y pertenecientes a la Ohio State University, Universidad Autónoma de Madrid, Universidad Autónoma de Barcelona, Universitat Pompeu Fabra, Universidad de Santiago de Compostela y el Instituto de Estudios Sociales de Andalucía-Consejo Superior de Investigaciones Científicas.

6. En la literatura clásica, encontramos tres tipos de explicaciones de la participación política no convencional que podemos considerar complementarias. Por un lado, el modelo socioeconómico (Barnes y Kaase, 1979) enfatiza la importancia de la edad, el sexo y el nivel de educación como las variables explicativas más importantes de la participación en protestas. Otra línea de investigación señala la importancia explicativa de los factores sociopolíticos (ideología, afinidad partidista, interés por la política, pertenencia a organizaciones sociales, etc.). Habitualmente, ser progresista (de izquierdas), estar interesado por la política y pertenecer a organizaciones sociales, son condicionantes que aumentan las probabilidades de participación no convencional. Por su parte, la literatura sobre movimientos sociales ha enfatizado la incidencia de motivaciones del contexto político (las oportunidades políticas) y el papel de las estructuras organizativas en la naturaleza de la movilización (teoría de la movilización de recursos).

7. Véanse, entre otros, Norris (2000), Klingemann y Fuchs (1995) y Dalton (1996).

8. En los estudios electorales, se habla de un proceso de desalineamiento (dealigment), tanto psicosocial (pérdida de influencia de la identificación partidista sobre el voto) como sociológico (pérdida de influencia de la identificación de clase). 
de cambio. Detrás de estas tendencias, parece operar un proceso de individualización de la política (Dalton, 2000), que genera ciudadanos más críticos (Norris, 1999; Fuchs y Klingemann, 1995), electoralmente más volátiles, y donde la movilización política estaría cada vez menos fundamentada en la posición social de los ciudadanos y la mediación de identidades fuertes (como las tradicionalmente vinculadas a la identificación partidista o los sindicatos), y más en las actitudes individuales hacia temas específicos de interés personal (más cambiantes en el tiempo). En cuanto a las implicaciones para el funcionamiento de las democracias, la extensión de la protesta, contrariamente a la interpretación basada en la desafección democrática, lejos de suponer una amenaza desestabilizadora, se podría interpretar como uno de los principales canales a disposición de los ciudadanos para hacer oír su voz en las democracias representativas?.

A partir de estas líneas argumentativas, estos estudios señalan la existencia de un proceso de normalización de la protesta de acuerdo con el cual no sólo sería más frecuente el recurso a la protesta, sino que el potencial de movilización se estaría extendiendo a sectores más amplios de la sociedad ${ }^{10}$, lo que aumentaría la heterogeneidad de los ciudadanos que participan en las protestas y, consecuentemente, matizaría la influencia de las variables sociodemográficas. No obstante, y teniendo en cuenta que los rasgos de los participantes varían según la naturaleza de las demandas y de los procesos de movilización, en términos generales se puede afirmar que el proceso de normalización es más cierto en cuanto a la mayor participación de la mujer y, con matices, la edad de los participantes. Por el contrario, el nivel educativo se mantiene como un factor predictivo crucial (precisamente, alimentado por ese proceso de individuación de los fundamentos de la participación en los que los recursos cognitivos ganan, aún si cabe, mayor importancia) ${ }^{11}$.

La expresión paradigmática de este proceso de normalización de los asistentes a manifestaciones la encontraríamos en aquellas movilizaciones en las que las emociones desempeñan un papel movilizador fundamental (Van Aelst y Walgrave, 2001: 477), mediante la politización de los afectados moralmente por un crimen o una injusticia. El potencial de movilización de este tipo de manifestaciones es muy amplio, ya que se ve menos afectado por las diferencias que las variables sociodemográficas y políticas (como la afinidad partidista) introducen en la protesta ${ }^{12}$. En España, este tipo de movilizaciones podría ilus-

9. Sobre la relación entre los movimientos sociales y la democracia representativa, véase Casquete (2003).

10. La reducción del coste de la participación en protestas pacíficas (asociada al aumento de legitimidad, el reconocimiento como derecho democrático, la mayor eficacia movilizadora de organizaciones intermedias, etc.) subyace a esta tendencia.

11. Véanse Topf (1995) y Norris (2002). Aunque no es la norma en las democracias occidentales, en el caso español, Barreiro (2002) ha señalado la mayor desigualdad de la participación no convencional frente al voto.

12. Como indican estos autores, en estos procesos de movilización, más que las estructuras partidistas, son los medios de comunicación los que desempeñan un papel movilizador fundamental. 
trarse con las manifestaciones contra el terrorismo como las registradas con motivo del asesinato de Miguel Ángel Blanco en 1997 o los atentados del $11-\mathrm{M}$ en $2004^{13}$. Aunque las manifestaciones del $15-\mathrm{F}$ no se ajustan del todo a este tipo de movilizaciones, podemos considerar que poseen una dimensión emocional importante vinculada a los sentimientos de solidaridad con las víctimas civiles o de injusticia ante la naturaleza del proceso de toma de decisiones al margen de la ONU, en contra de la opinión pública, etc. Parece razonable pensar que la existencia de este componente moral (con una dimensión emocional fuerte que transciende afiliaciones políticas y grupos sociales) podría haber extendido la base de los participantes potenciales a amplios sectores sociales.

La segunda faceta teórica de este trabajo se refiere a la comprensión de la relación entre la protesta social y la participación electoral y, en concreto, a los efectos electorales de la protesta; cuestión ésta a la que la literatura (tanto en el campo de los movimientos sociales como del comportamiento electoral) ha prestado una atención insuficiente ${ }^{14}$. En la medida en que se produce el mencionado proceso de desalineamiento político, en la explicación del comportamiento electoral ganan relevancia factores explicativos contextuales, como la percepción de los ciudadanos de la coyuntura económica, las cualidades de los candidatos o la posición de los partidos ante los temas (issues) más salientes para la opinión pública. El componente contingente de estas variables explicaría la mayor volatilidad del voto entre un electorado cada vez más sofisticado y que se comporta con mayor autonomía frente a los partidos y a los gobiernos. En concreto, la importancia del llamado voto temático permite establecer una conexión directa entre la participación en protestas sobre cuestiones concretas y el comportamiento electoral ${ }^{15}$.

En este sentido, este trabajo también se plantea como objetivo explorar el potencial de dicho tipo de investigaciones empíricas centradas en los participantes en eventos específicos como estrategia metodológica para generar conocimiento sobre los efectos electorales de la protesta social ${ }^{16}$. La naturaleza multitudinaria de la manifestación del 15-F y la relevancia de la problemática en las elecciones de 2004 ofrecen una oportunidad sin precedentes para este tipo de indagaciones.

13. En el primer caso, el eslogan «Basta Ya» refleja esa politización de los sentimientos de los afectados por el asesinato, así como su bajo perfil partidista (Van Aelst y Walgrave, 2001: 478). No obstante, cabe señalar la tendencia reciente hacia una mayor confrontación partidista en las manifestaciones contra el terrorismo en España.

14. La incidencia electoral de la protesta en el ámbito de la política local es mucho más clara (véase, por ejemplo, Jiménez 2005, para el caso de la protesta ambiental)

15. El establecimiento de esta conexión es, al mismo tiempo, congruente con la interpretación de la protesta social como un mecanismo de participación habitual en las democracias representativas, más que como un síntoma de desafección democrática o un elemento de disfuncionalidad.

16. En este sentido, aunque utilizando encuestas convencionales, una línea de investigación importante es la realizada por Verba y otros (1990), quienes han señalado la importancia de la protesta a la hora de mostrar a los responsables políticos la existencia de públicos e issues salientes. 


\section{Los datos: la encuesta IPPS en España}

Como hemos mencionado, los datos analizados corresponden a la muestra española de la encuesta International Peace Protest Survey, realizada en las principales manifestaciones de diversos países europeos y EEUU, utilizando un mismo cuestionario, traducido y con pequeñas adaptaciones al contexto nacional, para ser autocumplimentado y devuelto por correo. En España, la encuesta se realizó entre los participantes durante la manifestación del 15-F en Madrid. En total, se distribuyeron 1.200 cuestionarios $^{17}$, siendo devueltos 452 cuestionarios válidos. La tasa de respuesta (38\%) se situó dentro de nuestras expectativas. Encuestar a los participantes en manifestaciones es una técnica relativamente novedosa, por lo que debemos detenernos brevemente en su descripción, señalando las estrategias seguidas para asegurar la representatividad de la muestra respecto al universo de manifestantes.

Los cuestionarios fueron distribuidos durante las manifestaciones siguiendo un mismo método de encuestación, previamente utilizado con éxito en investigaciones similares en Bélgica (véase Van Aelst y Walgrave, 2001, y Norris, Walgrave y Van Aelst, 2005) ${ }^{18}$.

Este tipo de encuestas tienen que hacer frente a dos problemas específicos que pueden afectar seriamente a su representatividad: la distribución no homogénea de los participantes en el espacio de la manifestación ${ }^{19}$ y el sesgo introducido por el procedimiento seguido de autocumplimentación y devolución postal. En cuanto al primero, los entrevistadores siguieron un protocolo, con objeto de distribuir los cuestionarios de la manera más homogénea posible a lo largo de todo el espacio ocupado por la manifestación ${ }^{20}$. Para controlar el posible sesgo introducido por el procedimiento de administración (autocumplimentado y devolución postal), en algunas manifestaciones, aunque no en el caso de Madrid, se realizaron también un número reducido (100) adicional de entrevistas cara a cara (in situ), con el objetivo de comprobar la representatividad de la muestra postal. Los resultados de esta comparación, señalan

17. Labor en la que participó un equipo de más de 20 voluntarios, a los que agradezco su colaboración desinteresada.

18. La metodología desarrollada por Walgrave y sus colaboradores recoge también la propuesta desarrollada por Favre, Mayer y Fillieule ( 1997) para garantizar las mismas posibilidades para todos los participantes de ser entrevistados. La codificación de las encuestas se realizó de manera centralizada, minimizando los problemas de integración de las distintas muestras. Para obtener más información sobre la investigación y el procedimiento de encuestación, véase Walgrave y Verhust (2003) o la página web del proyecto (http://webhost.ua.ac.be/m2p/IPPS/ intro.htm), donde además se puede consultar el cuestionario utilizado.

19. Los manifestantes suelen agruparse por bloques según un orden establecido por los convocantes, alrededor de pancartas, etc.

20. Una vez iniciada la marcha, los entrevistadores se situaron a lo largo de todo el espacio ocupado por los manifestantes e iniciaron el reparto seleccionando una persona cada diez según avanzaba la manifestación. Todos los entrevistadores seguían una misma estrategia a la hora de invitar a los manifestantes a aceptar el cuestionario, rellenarlo y devolverlo por correo (cada cuestionario incluía un sobre con franqueo en destino). 
como principal sesgo, el (aún) mayor nivel de estudios de los manifestantes que depositaron la encuesta en el buzón de correos.

De esta manera, podemos pensar que las muestras postales son bastante representativas del universo de manifestantes, aunque posiblemente los niveles de estudios bajos estén infrarrepresentados. Como se comprobará en las siguientes páginas, la congruencia de los resultados obtenidos con los obtenidos en investigaciones sobre comportamiento político no convencional, basados en encuestas para la población en general, aumenta la confianza sobre la representatividad de nuestra muestra. La riqueza de la información obtenida a través de este método, relativamente económico, le confiere un alto valor añadido frente a otras estrategias de encuestación.

\section{La movilización contra la guerra y el perfil político de los participantes}

La manifestación del 15-F se inserta dentro de las movilizaciones pacifistas en las que tradicionalmente los sectores progresistas han desempeñado un papel protagonista. No obstante, el pacifismo no es un valor moral exclusivo de la izquierda. Como refleja, por ejemplo, el posicionamiento contrario a la guerra del Vaticano, los sectores más religiosos, con frecuencia también más conservadores, pueden igualmente defender los valores de la paz. De hecho, el alto porcentaje de ciudadanos que se mostraron contrarios a la intervención militar en Irak, sugiere la presencia del pacifismo como un valor consolidado en la cultura política dominante de los españoles, que recorrería transversalmente las distintas posiciones ideológicas ${ }^{21}$. En este sentido, la existencia de un discurso que considera la guerra injusta e inmoral, la preocupación por el daño a la población civil, así como la sensación generalizada de que los gobernantes no estaban teniendo en cuenta la opinión de la mayoría de los españoles, son elementos que amplían el potencial de movilización a grandes sectores de la sociedad, y que, a priori, actuarían a favor de una mayor diversidad entre los participantes (con lo que aumentaría su representatividad respecto al conjunto de la población). Al mismo tiempo, la explicación de las decisiones de manifestarse o no de estos sectores puede considerarse altamente condicionada por el contexto político en el que se producen los procesos de movilización. Como se ha indicado, en España, la manifestación convocada por organizaciones sociales (dentro de la convocatoria del movimiento altermundista) adquiere un carácter de confrontación política entre la derecha en el Gobierno y la oposición de izquierdas (del PSOE, de IU y de los sindicatos). Sin duda, esta coyuntura política amplió el volumen de participación y explica el éxito de las moviliza-

21. En los meses previos a la intervención militar en Irak, los sondeos de opinión reflejan una oposición mayoritaria, casi unánime, contraria la guerra. El barómetro del CIS de febrero de 2004 (estudio n. ${ }^{\circ}$ 2.481), la guerra de Irak aparece como el tercer problema principal de España (con un 27,5\% detrás del paro, 69\%, y el terrorismo 47,9\%). En el mismo sondeo, un $70 \%$ de la población se mostraba nada de acuerdo con la (inminente) intervención militar, un $21 \%$ poco de acuerdo, y sólo un $5 \%$ estaba de acuerdo o bastante de acuerdo. 
Tabla 1. Distribución porcentual de los participantes en el 15-F de acuerdo con su conducta electoral reciente (y recuerdo de voto) y su índice de representatividad en relación con los resultados en las elecciones generales de 2000.

\begin{tabular}{|c|c|c|c|c|}
\hline & \multicolumn{2}{|c|}{ IPPS-Spain } & $\begin{array}{l}\text { Resultados en las elecciones } \\
\text { generales de } 2002 \\
\text { (\% sobre el electorado) }\end{array}$ & $\begin{array}{l}\text { Índice de } \\
\text { representatividad (a) }\end{array}$ \\
\hline & $N$ & $\%$ válido & & \\
\hline PP & 44 & 10,0 & 29,5 & 0,34 \\
\hline PSOE & 186 & 42,3 & 22,6 & 1,87 \\
\hline IU & 88 & 20,0 & 3,6 & 5,56 \\
\hline Otros & 13 & 3,0 & 10,6 & 0,28 \\
\hline Blanco / abstención política* & 71 & 16,1 & $33,6^{* *}$ & \\
\hline No votó (por edad / de viaje) & 38 & 8,6 & & \\
\hline TOTAL & 440 & 100,0 & 100,0 & \\
\hline Votó (NC) & 10 & & & \\
\hline Perdidos & 2 & & & \\
\hline$N$ & 452 & & & \\
\hline
\end{tabular}

(a) El índice de representatividad es la razón entre el porcentaje recuerdo de voto en la encuesta y el porcentaje de votantes en las elecciones generales de 2000.

* Los abstencionistas políticos son aquellos manifestantes que justifican su abstención señalando la ausencia de partidos que reflejen sus intereses o no creer en la democracia representativa.

** Incluye los votos en blanco, nulos y la abstención

Fuente: ISSP 2003-Spain y Ministerio del Interior (http://www.elecciones.mir.es/).

ciones $^{22}$, pero, al mismo tiempo, favoreció una mayor homogeneidad política de los asistentes (Walgrave y otros, en preparación).

Efectivamente, como puede observarse en la tabla 1, con datos sobre comportamiento electoral pasado, la manifestación del 15-F movilizó fundamentalmente a votantes de partidos de izquierdas: un $42 \%$ de los participantes había votado al PSOE y un $20 \%$ a IU. No obstante, aunque de manera minoritaria $(10 \%)$, encontramos votantes de derechas. Igualmente, cabe destacar la presencia de abstencionistas. En concreto, un $16 \%$ puede considerarse como abstencionistas políticos, ya que votaron en blanco o no votaron por no creer en la democracia representativa o considerar que ninguna de las candidaturas reflejaba sus intereses.

22. Aunque, sin duda, el factor movilizador crítico fue la labor de difusión de los medios de comunicación. Una breve revisión de las noticias en prensa y televisión basta para comprobar la amplía difusión que la convocatoria tuvo durante los días previos. También reflejaría la desigual atención según las afinidades políticas de los medios. Esta desigualdad en el tratamiento mediático del evento es un indicador de la importancia del componente político frente al emocional (moral) en el proceso de movilización. 
El sesgo partidista de los participantes en la manifestación se puede estimar mejor utilizando como criterio de representatividad los resultados electorales de las elecciones generales de 2000 . Pese a los problemas de validez de este índice ${ }^{23}$, resulta posible hablar de una clara sobrerrepresentación de votantes de IU (con una presencia cinco veces superior a su peso electoral) y del PSOE, mientras que tanto los votantes de PP y de otros partidos, estuvieron infrarrepresentados. Igualmente, aunque no hemos calculado el índice de representatividad para los abstencionistas, los datos sugieren que estaban infrarrepresentados en la manifestación.

En breve, estos resultados indican dos rasgos básicos del comportamiento electoral de los asistentes a la manifestación. En primer lugar, encontramos tantos votantes o más que entre la población en general, lo que refuerza la interpretación de la participación en manifestaciones como una ampliación del repertorio político de los ciudadanos, más que como una alternativa al voto en las democracias representativas. En segundo lugar, los datos señalan la importancia de las afinidades partidistas en la configuración del mapa político de los manifestantes. Pese a la amplia opinión mayoritaria de los españoles contraria a la intervención militar en Irak, fueron los ciudadanos más cercanos a los dos partidos de la oposición los que participaron masivamente en la jornada de protesta. Podemos pensar en al menos dos argumentos que explican esta mayor presencia de los votantes de izquierda. Como hemos mencionado, el componente de crítica al Gobierno no sólo ánima al electorado de la oposición, sino que también inhibe a los votantes del PP, de tal manera que la lealtad a su partido actúa como freno a la participación. Por otro lado, también se puede argumentar que los sectores conservadores no participan de la experiencia de movilización a favor de la paz en la misma medida que la izquierda ${ }^{24}$. Es decir, pese a la existencia de un proceso de normalización de la protesta, la ideología (y la socialización política) son factores relevantes para explicar la participación en protestas, al menos en este tipo de manifestaciones. No obstante, una interpretación del 15-F centrada exclusivamente en la dimensión de la confrontación entre el Gobierno y la oposición resultaría excesivamente simplista. La presencia de un porcentaje significativo de votantes del PP y de abstencionistas políticos indica la confluencia en las calles de las ciudades españolas de sectores sociales con distintos perfiles políticos y motivaciones diversas.

De acuerdo con estos resultados relativos a la conducta electoral pasada, podemos diferenciar cuatro sectores o tipos de manifestantes: (1) votantes del PP, (2) votantes del PSOE, (3) votantes de IU y (4) abstencionistas políticos. En los siguientes apartados, trazamos el perfil de estos sectores (y del conjun-

23. Estamos comparando resultados para todo el territorio con la conducta expresada por manifestantes en Madrid.

24. Ya sea, en el caso de los adultos, en torno a las movilizaciones contra la entrada de España en la OTAN o, entre las generaciones más jóvenes, en relación con la oposición a la mili (y la objeción). Sobre el impacto cultural de la protesta pacifista en España, véase Prat, 2003. 
to de manifestantes) en función de una selección de indicadores de tipo sociodemográfico, de actitudes y de comportamiento político, tradicionalmente utilizados en los estudios sobre participación política.

\section{Rasgos sociodemográficos de los participantes del 15-F}

El interés que guía este análisis no se centra tanto en la identificación de las desigualdades en términos sociodemográficos de los manifestantes respecto a la población en general, como en la caracterización de los diversos sectores que confluyen en la manifestación. No obstante, el contraste con la población en general nos ofrece una imagen global de los rasgos de los participantes a partir de la que caracterizar sus componentes. En concreto utilizamos los índices de representatividad relativos a las tres variables sociodemográficas tradicionalmente utilizadas en los estudios del modelo socioeconómico de la participación: el sexo, la edad y el nivel educativo ${ }^{25}$.

Los índices de representatividad señalan que los participantes no se diferencian de la población en general por la mayor o menor presencia de mujeres. Como hemos señalado, en el terreno de las desigualdades de género es donde más se ha avanzado en el proceso de normalización de la protesta. En cuanto a la edad, los índices indican la mayor presencia de los grupos de edad intermedios (los adultos jóvenes y adultos, entre 25 y 64 años), siendo especialmente escasa la presencia relativa de mayores de 65 años. Por último, el nivel educativo se mantiene como la mayor fuente de desigualdad de los participantes respecto a la población en general ${ }^{26}$. Estos resultados indican que los manifestantes del 15-F constituyen un grupo sociodemográfico relativamente homogéneo y que no representa al conjunto de la población. Como muestra la tabla 2, dentro de esta homogeneidad sociodemográfica apenas existen pequeñas variaciones entre distintos sectores políticos que hemos identificado.

Así, las diferencias en función del sexo o del nivel de estudios son pequeñas (o no resultan significativas). Es decir, los participantes dentro de los cuatro sectores identificados poseen un mismo nivel medio de estudios que, como hemos señalado, es muy alto (estudios universitarios) ${ }^{27}$. Sólo, en términos de edad media, podemos afirmar que el sector de votantes del PP se diferencia

25. Véase la tabla A.2 en el anexo. Estos resultados son congruentes con estudios sobre la desigualdad en diferentes formas de participación en España (Barreiro, 2004) y con el trabajo realizado por Caínzos y Gayo (2003) sobre participación en actos de protesta contra la guerra de Irak, ambos basados en encuestas del CIS.

26. Se confirma el nivel de estudios como uno de los principales límites al proceso de normalización de la protesta anteriormente mencionado, siendo más significativa su incidencia conforme aumentan los recursos cognitivos que requieren las distintas formas de participación política. Como hemos señalado, el procedimiento de encuestación (cuestionario postal autocumplimentado) puede haber introducido un sesgo precisamente a favor de estos sectores.

27. Este sesgo se habrá visto acentuado por el procedimiento de encuestación mediante cuestionario autocumplimentado a devolver por correo. 
Tabla 2. Perfil sociodemográfico de los participantes de acuerdo con su conducta electoral.

\begin{tabular}{llllr}
\hline & \% de mujeres & Edad media & Nivel de estudios (1) & $N$ \\
\hline Total & 52,0 & 40,2 & 3,4 & 440 \\
\hline PP & 50,0 & $35,5^{*}$ & 3,6 & 44 \\
PSOE & 49,5 & $43,9^{*}$ & 3,4 & 186 \\
IU & 53,4 & 41,1 & 3,4 & 88 \\
Otros & 53,8 & 40,7 & 3,3 & 13 \\
Blanco / abstención política & 57,7 & 39,2 & 3,5 & 71 \\
No votó (por edad / de viaje) & 52,6 & $26,6^{*}$ & 3,1 & 38 \\
\hline
\end{tabular}

* Diferencias de medias significativas (nivel de confianza del 95\%).

(1) Los valores medios en una escala de 1 a 5 , donde 1 significa: "hasta primarios», 2: "estudios de secundaria», 3: «universitarios medios», 4: «universitarios superiores», 5: "postgrado».

Fuente: IPPS2003-Spain.

del conjunto de manifestantes fundamentalmente por su edad media inferior, mientras que los votantes del PSOE se diferencian por una edad media significativamente más alta. Los abstencionistas también se desvían de la media por una edad media significativamente menor que la del conjunto de la muestra y un mayor porcentaje de mujeres (aunque esta última diferencia no llega a ser estadísticamente significativa).

\section{Perfil actitudinal de los participantes en el 15-F}

Junto a los rasgos sociodemográficos, la literatura ha destacado los factores actitudinales como variables explicativas de la participación política no convencional. En concreto, hemos analizado el perfil de los distintos sectores de acuerdo con la autoubicación ideológica, el interés por la política y la satisfacción con la democracia ${ }^{28}$. Junto a estos tres indicadores de actitudes políticas generales, se han considerado también el nivel de religiosidad (catolicismo) y la actitud hacia el movimiento de justicia global ${ }^{29}$.

Como puede observarse en la tabla 3, en términos generales, los manifestantes son personas de izquierdas, interesadas en la política y críticas con el funcionamiento de la democracia. Estos resultados son congruentes con los

28. En este último caso, la relación es inversa: a mayor descontento con el funcionamiento de la democracia, mayor la probabilidad de participar en formas no convencionales d'intervenció política (Dalton, 1996).

29. La inclusión de estos dos indicadores atiende a la naturaleza específica de esta manifestación: resulta razonable pensar que estas variables pueden estar asociadas de manera diferente con la participación de los diversos sectores de manifestantes. 
Tabla 3. Perfil sociopolítico de los participantes de acuerdo con su conducta electoral. Posiciones medias.

\begin{tabular}{|c|c|c|c|c|c|}
\hline & $\begin{array}{l}\text { Ubicación } \\
\text { ideológica } \\
\text { (1) }\end{array}$ & $\begin{array}{l}\text { Interés por } \\
\text { la política } \\
\text { (2) }\end{array}$ & $\begin{array}{l}\text { Satisfacción } \\
\text { democracia } \\
\text { (3) }\end{array}$ & $\begin{array}{l}\text { Religiosidad } \\
\text { (4) }\end{array}$ & $\begin{array}{l}\text { Proximidad } \\
\text { movimiento } \\
\text { altermundista } \\
\text { (5) }\end{array}$ \\
\hline Total & 2,6 & 2,2 & 2,7 & 2,5 & 3,2 \\
\hline $\mathrm{PP}$ & $4,8^{*}$ & $2,6^{*}$ & $2,4^{*}$ & $2^{*}$ & $3,5^{*}$ \\
\hline PSOE & $2,3^{*}$ & $2,0^{*}$ & $2,5^{*}$ & 2,5 & 3,3 \\
\hline IU & $2,1^{*}$ & $2,0^{*}$ & $2,9^{*}$ & $2,7^{*}$ & $2,9^{*}$ \\
\hline Otros & 2,7 & 2,0 & 3,0 & 2,6 & 3,0 \\
\hline Blanco / abstención política & 2,6 & $2,6^{*}$ & $3,0^{*}$ & $2,7^{*}$ & 3,1 \\
\hline No votó (por edad / de viaje) & 2,8 & 2,2 & 2,9 & 2,6 & $3,5^{*}$ \\
\hline$N$ (válido) & 395 & 450 & 440 & 426 & 428 \\
\hline
\end{tabular}

* Diferencias de medias significativas (nivel de confianza del 95\%).

(1) Escala de 0 a 10 (donde 0 es «extrema izquierda» y 10, «extrema derecha»).

(2) Escala de 1 a 5 (donde 1 es «muy interesado» y 5 «nada interesado»).

(3) Escala de 1 a 4 (donde 1 es "totalmente satisfecho» y 4 "nada satisfecho»).

(4) Escala de 1 a 3 (donde 1 es «católico practicante», 2 «católico no-practicante» y 3 «no creyente»).

(5) Escala de 1 a 4 (donde 1 es «activista», 2 «sociopasivo / participante en manifestaciones contra la globalización neoliberal», 3 «simpatizante» y 4 «nada identificado con el movimiento»).

Fuente: IPPS2003-Spain.

resultados obtenidos generalmente por los estudios de participación política no convencional (Dalton, 1996; Barreiro, 2004). La comparación entre los distintos sectores arroja mayor variabilidad y permite diferenciarlos en mayor medida que en función de las variables sociodemográficas.

Los manifestantes se ubican predominantemente en la parte izquierda del espectro ideológico ${ }^{30}$, situándose, como cabría esperar, los votantes del PP en las posiciones más hacia la derecha y los de IU, más a la izquierda. En cuanto al interés por la política, el contraste de medias indica un mayor interés entre los votantes de izquierdas (PSOE y IU) e inferior a la media entre los sectores de abstencionistas políticos y de votantes del $\mathrm{PP}^{31}$. Respecto a estos dos últimos grupos, cabe realizar una interpretación distinta para cada caso. Mientras que,

30. La media en la escala ideológica se sitúa muy a la izquierda, en el 2,6 (habitualmente, se sitúa alrededor del 4-5). En todos los casos, además, se ubican a la izquierda respecto del conjunto de votantes de los distintos partidos y de los abstencionistas.

31. Respecto a las diferencias de cada grupo con el conjunto de electores, cabe señalar el menor interés relativo de los votantes del PSOE en el total del electorado. En su conjunto, en cuanto a su interés por la política, los votantes del PSOE suelen parecerse más a los votantes del PP que a los de IU, mientras que, entre los participantes, se acercan más a los electores de IU. 
para los últimos, el desinterés por la política se explicaría por el conservadurismo, en el caso de los abstencionistas políticos estaríamos ante una expresión más de rechazo a la política dominada por actores (partidos políticos) con los que no se identifican e instituciones de democracia representativa ante las que se muestran disconformes. Esta interpretación parece respaldada por las divergencias en las puntuaciones medias de ambos sectores en relación con el indicador de satisfacción con la democracia. El sector más cercano al PP coincide aquí con los votantes del PSOE en su actitud menos crítica que la media de los participantes. Por el contrario, la abstención política y los votantes de $\mathrm{IU}$ engloban a los sectores sociales que expresan una mayor insatisfacción con el funcionamiento de la democracia ${ }^{32}$.

Respecto a la religiosidad, los votantes de IU y la abstención política coinciden en su laicidad frente a la mayor proporción de católicos (y católicos practicantes) entre los votantes del PP. Éstos son también los participantes que más lejos se sitúan respecto al movimiento de justicia global. En este sentido, de nuevo el sector de votantes de IU aparece en la posición opuesta, con una puntuación media que los sitúa significativamente como el sector más cercano al movimiento.

\section{Perfil conductual de los participantes en el 15-F}

En este apartado, atendemos a dos variables habitualmente asociadas con la participación en la protesta: la experiencia previa en actos similares y la pertenencia a organizaciones. En primer lugar, la tabla 4 caracteriza a los distintos sectores políticos de acuerdo con los valores de cuatro indicadores de participación en manifestaciones: (1) porcentaje de participantes en manifestaciones pacifistas previas; (2) porcentaje de asistentes para los que el 15-F supuso su primera experiencia (en los cinco últimos años); (3) porcentaje de participantes experimentados (con más de cinco manifestaciones en lo últimos cinco años), y (4) número de tipos distintos de manifestaciones en las que han participado.

En términos generales, los resultados indican que todos los asistentes poseen un perfil político no-convencional alto. Un $43 \%$ de los participantes declara haber participado previamente en manifestaciones pacifistas. Un $25 \%$ puede ser considerado como manifestante experimentado frente al $20 \%$ de participantes noveles. Dentro de este perfil general, y aunque los contrastes no llegan a ser significativos estadísticamente, el sector de votantes del PP se diferencia por la menor experiencia de sus integrantes. Con todo, un 36\% afirma haber participado previamente en manifestaciones de tipo pacifista (el porcentaje más bajo de todos los participantes). Para un $25 \%$ la manifestación del 15-F significó su primera experiencia de este tipo, y sólo un

32. Estas diferencias entre los manifestantes son congruentes con las que las encuestas arrojan para el conjunto de la población. 
Tabla 4. Experiencia política de los participantes de acuerdo con su conducta electoral.

\begin{tabular}{lllll}
\hline & $\begin{array}{l}\text { Porcentaje } \\
\text { de participación } \\
\text { previa en } \\
\text { manifestaciones } \\
\text { pacifistas }\end{array}$ & $\begin{array}{l}\text { Porcentaje de } \\
\text { primerizos }\end{array}$ & $\begin{array}{l}\text { Porcentaje de } \\
\text { experimentados }\end{array}$ & $\begin{array}{l}\text { Número (medio) } \\
\text { de tipos } \\
\text { distintos de } \\
\text { manifestaciones } \\
(1)\end{array}$ \\
\hline Total & 42,5 & 20,5 & 26,0 & 2,1 \\
\hline PP & 36,4 & 25,0 & $13,6^{* *}$ & $1,4^{*}$ \\
PSOE & 38,7 & 18,0 & 27,3 & 2,0 \\
IU & 51,1 & 19,5 & 32,2 & $2,5^{*}$ \\
Otros & 61,5 & 16,7 & 41,7 & 2,1 \\
Blanco / abstención política & 40,8 & 24,3 & 24,3 & 2,2 \\
No votó (por edad / de viaje) & 44,7 & 23,7 & 18,4 & 1,8 \\
\hline$N$ & 440 & & 434 & 440 \\
\hline
\end{tabular}

* Diferencias de medias significativas (nivel de confianza del 95\%).

** Variaciones de casilla significativas (por encima o por debajo de la frecuencia esperada; nivel de confianza del 95\%).

(1) De 0 a 11 tipos; incluye pacifistas, contra el racismo, solidaridad con los países en desarrollo, DDHH, temas sociolaborales, medioambientales, contra la globalización, por los derechos de las mujeres, regionales, contra el terrorismo, otras. Originalmente, se codificaron 10 categorías a las que posteriormente se añadió, a partir de la recodificación de «otras», la opción «contra el terrorismo».

Fuente: IPPS2003-Spain.

$14 \%$ ha participado en más de cinco. En el extremo opuesto, los votantes de otros partidos y, en especial, de IU poseen historiales de protesta más amplios.

Las diferencias en términos de participación en tipos distintos de manifestaciones también sitúan a los votantes del PP y de IU en los extremos opuestos. La experiencia de los votantes conservadores se centra en manifestaciones relacionadas con demandas sociolaborales (39\% por debajo del porcentaje del $51 \%$ para el total de la muestra), y destacan especialmente por ser el grupo con un mayor porcentaje de participación en manifestaciones contra el terrorismo (un 16\% frente al 10\% del total). Por su parte, los votantes del PSOE y de IU se distinguen por su mayor experiencia en manifestaciones de tipo sociolaboral: un $66 \%$ y un $64 \%$, respectivamente, afirman haber participado en este tipo de manifestaciones. Los votantes de IU destacan además por ofrecer los porcentajes más altos respecto a todas las manifestaciones (salvo las contrarías al terrorismo). En suma, los resultados señalan a los votantes de IU como los más próximos a la actividad de la protesta de los llamados «nuevos movimientos sociales», mientras que los votantes de los partidos mayoritarios se centran en las reivindicaciones clásicas, siendo las protestas contra el terro- 
Tabla 5. Participación en asociaciones de los participantes de acuerdo con su conducta electoral*.

\begin{tabular}{lccc}
\hline & $\begin{array}{l}\text { Porcentaje de } \\
\text { miembros } \\
\text { de asociaciones } \\
\text { pacifistas }\end{array}$ & $\begin{array}{l}\text { Porcentaje de } \\
\text { miembros } \\
\text { de asociaciones }\end{array}$ & $\begin{array}{l}\text { Número (medio) } \\
\text { de tipos distintos } \\
\text { de organizaciones } \\
(\mathbf{1})\end{array}$ \\
\hline Total & $\mathbf{6 , 8}$ & 54,6 & $\mathbf{1 , 7}$ \\
\hline PP & 7,0 & 58,1 & 1,8 \\
PSOE & 4,5 & 54,4 & 1,6 \\
IU & 8,3 & 62,8 & 2,2 \\
Otros & 15,4 & 46,2 & 1,4 \\
Blanco/ abstención política & 8,8 & 48,6 & 1,7 \\
No votó (por edad / de viaje) & 7,9 & 47,4 & 1,5 \\
\hline$N$ & 440 & 442 & 440 \\
\hline
\end{tabular}

* Ninguno de los indicadores arroja diferencias estadísticamente significativas.

(1) Valores medios en la escala de 0 a 14 tipos, que incluye las siguientes categorías: religiosa / parroquial, antirracista / pro inmigrantes, sindicato / profesional, partido político, deportiva / recreativa, ecologista, educativa / APA, vecinal, asistencial, antiglobalización, ONG desarrollo, pro derechos humanos, pacifistas y otras.

Fuente: IPPS2003-Spain.

rismo (con un componente emocional y, a priori, apartidista más alto) ${ }^{33}$ la experiencia de participación no-convencional más común entre los más conservadores.

La actividad en asociaciones aporta información adicional para completar el perfil conductual de los distintos sectores que participaron en el 15-F. Como puede observarse en la tabla 5, el porcentaje total de miembros de asociaciones es muy elevado: uno de cada dos pertenece al menos a una asociación ${ }^{34}$. Sin embargo, sólo un 7\% es miembro de organizaciones pacifistas. Este bajo porcentaje no es de extrañar si consideramos que sólo un 1\% de la población en general pertenece a este tipo de asociaciones ${ }^{35}$, e indica que el movimiento pacifista en España descansa organizativamente en estructuras de otros movimientos como el ecologista, las asociaciones de derechos humanos, ayuda al desarrollo, etc. Un resultado destacable es que el porcentaje de afiliación de los votantes del PP a este tipo de asociaciones se sitúa en la media, por delante de los participantes más cercanos al PSOE, lo que confirma la naturaleza transpartidista de los valores vinculados a la paz. No obstante, son los parti-

33. Como hemos mencionado, se trataría del tipo de manifestaciones en las que se aprecia mejor el proceso de normalización del perfil del participante en protestas.

34. Muy superior a la media de la población en general, lo que confirma la fuerte relación existente entre capital social y participación política no convencional.

35. Véase, por ejemplo, el estudio n. ${ }^{\circ} 2.450$ del CIS. 
dos más a la izquierda, IU y otros (entre los que figuran Los Verdes), los que engloban a un mayor porcentaje de miembros de este tipo de organizaciones.

Los dos indicadores restantes, pertenencia a asociaciones (en general) y afiliación múltiple (de acuerdo con distintos tipos de asociaciones), aportan algunas diferencias adicionales relevantes, aunque no son estadísticamente significativas. En relación con el porcentaje de manifestantes que pertenecen a asociaciones, podemos destacar el porcentaje inferior a la media total de miembros de organizaciones pacifistas entre los votantes del PSOE. Los resultados también distinguen a los votantes de IU seguidos de los votantes del PP como los sectores más frecuentemente vinculados a organizaciones sociales y con mayor afiliación múltiple ${ }^{36}$. La diferencia entre los votantes de IU y del PP radica precisamente en los tipos de organizaciones a los que pertenecen. Utilizando como referente los porcentajes totales de participación en cada uno de los distintos tipos de asociaciones, los votantes del PP destacan por su mayor afiliación a organizaciones de tipo religioso (16\% frente al $7 \%$ del total), ONG de desarrollo (32\% frente al $23 \%$ del total) y asistenciales (14\% frente al $10 \%$ total). Los votantes del PSOE se caracterizan por una presencia superior a la media en sindicatos, partidos políticos y asociaciones vecinales. Por su parte, los votantes de IU destacan por su vinculación a los sindicatos y a grupos de interés público, habitualmente soporte organizativo de los nuevos movimientos sociales. Los votantes de otros partidos destacan por su participación en asociaciones educativas, ONG de desarrollo, grupos pro derechos humanos y pacifistas. Por último, los englobados en el sector de abstencionistas políticos presentan un porcentaje de pertenencia a organizaciones antirracistas y ecologistas superior al resto.

\section{A modo de síntesis}

Los resultados anteriores permiten establecer el perfil sociopolítico de los principales sectores en los que hemos clasificado a los participantes en el 15-F de acuerdo con sus afinidades partidistas (conducta electoral pasada). Las diferencias entre estos sectores vienen marcadas, más que por factores sociodemográficos, por sus diferentes actitudes y comportamientos políticos. Así, el sector de votantes del PP se diferencia, en términos sociodemográficos, por una edad media inferior. En términos de sus actitudes políticas, por situarse ideológicamente en el centro (o más a la derecha que el resto de los grupos), por un menor interés por la política y por una mayor satisfacción con el funcionamiento de la democracia. También se caracterizan por su mayor catolicismo y su mayor distancia respecto al movimiento de justicia global. En términos de comportamiento político, se distinguen por una relativa menor experiencia en protestas, siendo su participación relativamente alta en las mani-

36. Estas diferencias (menor afiliación pacifista entre votantes del PSOE y mayor nivel de asociacionismo entre los votantes de IU) rozan los límites estadísticos de significatividad. 
festaciones contra el terrorismo. Por último, también se caracterizan por un nivel de activismo cívico (alto) similar a los demás grupos, orientado preferentemente a los sectores asociativos donde la Iglesia está presente. Si tuviéramos que buscar una etiqueta para este grupo, podríamos utilizar la de «jóvenes demócratas cristianos».

El grupo de votantes del PSOE se diferencia, en términos demográficos, por tener una edad media superior. En términos de actitudes, se caracteriza por ubicarse a la izquierda de la media de los manifestantes, así como por conjugar el interés por la política con la satisfacción con la democracia. En cuanto a su comportamiento político, muestra un nivel de experiencia algo superior por lo que se refiere a participación en protestas (siendo más frecuente su participación en manifestaciones motivadas por reivindicaciones tradicionalmente vinculadas al conflicto de clase); sin embargo, en cuanto a participación en asociaciones, el porcentaje parece algo menor que la media, estando orientada su participación a organizaciones tradicionales (como partidos políticos, sindicatos y asociaciones de vecinos). Podrían ser etiquetados como «socialdemócratas clásicos».

El sector de votantes de $I U$ aparece como el grupo más a la izquierda en el espectro ideológico y el que mejor se ajusta al fenómeno del cinismo político (interés por la política y crítico con el funcionamiento de la democracia). Se caracterizan, además, por su laicidad y cercanía al movimiento de justicia global. Acumulan la mayor experiencia en participación no convencional y actividad cívica, especialmente en el sector de los llamados «nuevos movimientos sociales». En comparación con el resto, podríamos referirnos a ellos como representantes de la izquierda alternativa o, también, como el núcleo de los sectores "críticos politizados»"

Por último, el grupo de abstencionistas políticos se distingue por cierta mayor feminización. En términos de actitudes políticas, reflejarían, mejor que ningún otro sector, el desencanto con la democracia y la individualización de la práctica política (menor interés por la política e insatisfacción con el funcionamiento de la democracia). Son predominantemente laicos y simpatizantes del movimiento de justicia global. Su nivel de participación no convencional y de actividad asociativa es relativamente inferior a los anteriores (aunque superaran a los votantes del PP en actividad no convencional). Podíamos llamarlos los «desencantados», que, quizás, frente a la apatía política, han optado por formas individualizadas de expresión política.

37. Como señala Norris (1999: 259) sobre la base de diversos estudios empíricos, los ciudadanos más cínicos presentan un perfil activo no convencional más alto. El cinismo político también ha sido asociado a los votantes de opciones políticas que persistentemente pierden las elecciones. En concreto, la autora estadounidense señala que el cinismo es más alto en países que producen perdedores en elecciones sucesivas, por ejemplo, en sistemas gobernados por uno o varios partidos predominantes que se enfrentan a oposiciones fragmentadas (Norris, 1999: 234). 


\section{Motivaciones para manifestarse contra la guerra}

Una vez trazado el mapa de los perfiles sociopolíticos de los manifestantes contra la guerra, cabe preguntarse en qué medida coinciden o difieren en cuanto a sus razones para manifestarse y las opiniones sobre la estrategia que debería seguir el Gobierno español ante la crisis de Irak. Nuestro cuestionario incluía una pregunta abierta acerca de las razones por las que los encuestados habían decidido participar en la manifestación. El primer resultado, quizás el más destacable, es el alto porcentaje de respuesta obtenido: un $98 \%{ }^{38}$. El gráfico 1

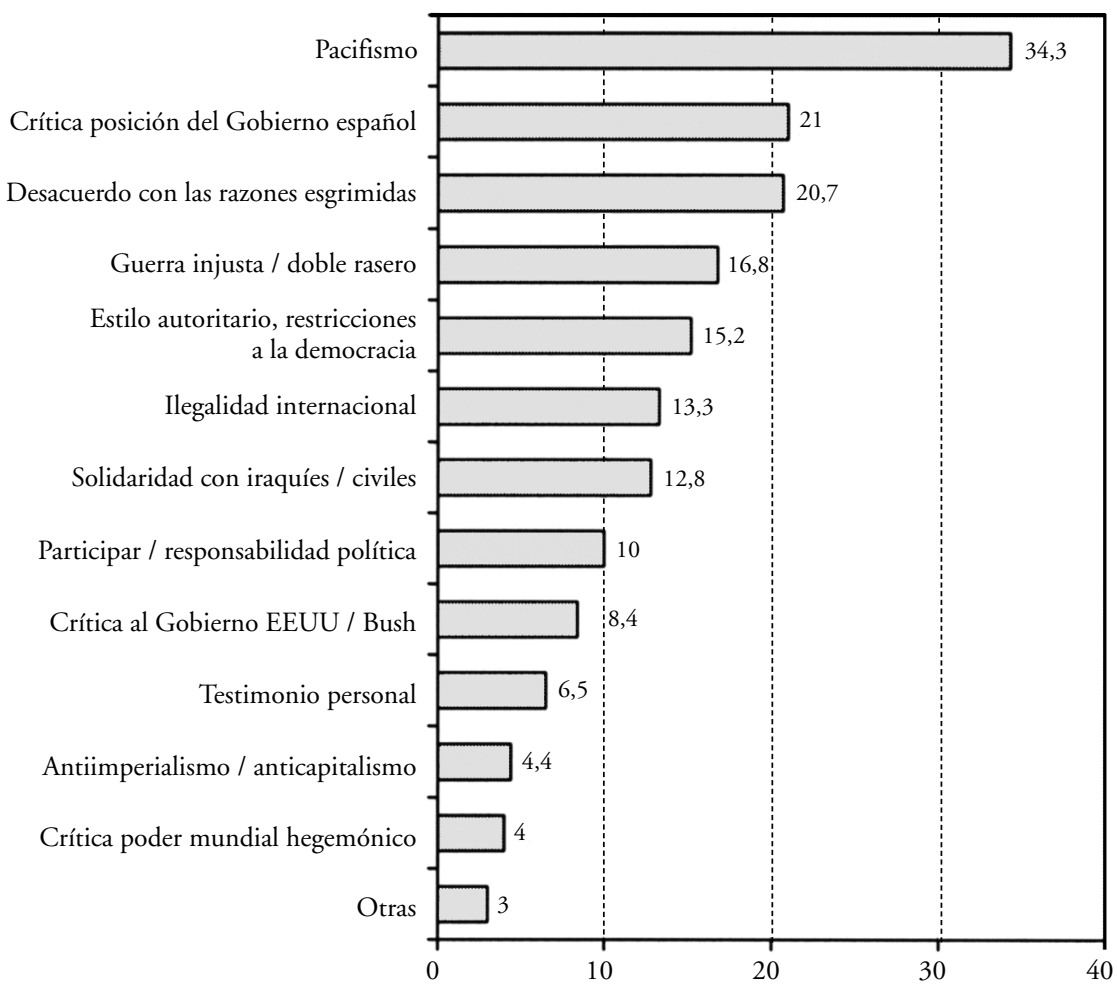

Gráfico 1. Razones (subjetivas) para participar en la manifestación del 15-F contra la guerra de Irak (porcentajes de fila).

Casos válidos: 441. Respuesta múltiple (\% de casos).

Cierre a la pregunta abierta "¿por qué decidió participar en esta manifestación?».

Fuente: IPPS2003-Spain.

38. Este alto porcentaje puede ser interpretado como un indicador del alto grado de motivación de los encuestados. La forma de administrar el cuestionario, que permite a los encuestados cumplimentarlo en casa, posiblemente ha favorecido esta tasa de respuesta. 
presenta los porcentajes de los distintos tipos de razones que reflejaban las respuestas una vez codificadas ${ }^{39}$.

La docena de motivos específicos diferentes que resultan del análisis de las respuestas obtenidas a la pregunta de «¿Por qué decidió participar en esta manifestación?» pueden a su vez agruparse en tres tipos de razones más generales: los dos primeros reflejan la incidencia de motivaciones que hemos señalado al principio de este trabajo: las de tipo político (de crítica política, con un componente partidista importante) y las de tipo moral, relacionadas con el valor de la paz y la no-violencia. Aunque son menos frecuentes, también aparecen un tercer tipo de razones que se refieren a la participación como razón (en sí) para manifestarse, ya sea como forma de expresión de opiniones y sentimientos individuales o como una responsabilidad ciudadana.

Las referencias al pacifismo (y la no-violencia) aparecen como la razón subjetiva más frecuente. Argumentos como «Me opongo a todas las guerras» o "Nunca puede haber argumentos a favor de la guerra», son expresados de manera espontánea por un $34 \%$ de los asistentes. En otro 4,4\% de los casos, encontramos un discurso cercano que alude al daño sobre la población civil y el sufrimiento del pueblo iraquí ${ }^{40}$. También dentro de las razones de tipo moral, aunque no necesariamente reflejo de valores pacifistas, están las que consideran la guerra como injusta y denuncian la existencia de un doble rasero a la hora de considerar violaciones del derecho internacional por parte de distintos países $(17 \%)^{41}$ o hacen referencia a la naturaleza ilegal de la intervención, al no contar con el respaldo del Consejo de Seguridad de la ONU (13\%).

Entre las justificaciones con un componente de crítica política más claro, aparecen con relativa frecuencia menciones a la falta de justificación de la guerra, criticando las razones esgrimidas por los líderes políticos a favor de la intervención (21\%) y, a veces, indicando los intereses económicos (y geopolíticos) como causa de la guerra («No más sangre por petróleo»). En la misma línea, otros participantes plantean un discurso crítico con la política de EEUU y, en particular, con su presidente (8\%). No obstante, el desacuerdo político tiene como blanco más frecuente al Gobierno del PP. En este sentido, se han identificado dos elementos discursivos diferentes: la crítica a la posición pro guerra del Gobierno (21\%) y la crítica a su actitud autoritaria, sorda a la opinión pública $(15 \%)^{42}$. Otro tipo de razones con un alto componente ideológico

39. Para cada encuestado se han codificado hasta un máximo de cinco razones o motivos, por orden de aparición en su respuesta.

40. Ejemplos: «Porque carece de sentido masacrar a un pueblo incluso cuando tiene un dictador»; «Porque me parece repugnante el desprecio que existe por la vida humana y el profundo respeto que se da al dinero»; «Por el derecho a la vida (una vez nacidos), y por considerar que la población no es culpable (responsable) de los desmanes de sus gobernantes».

41. Ejemplos: «Porque el ataque a Irak es injusto y desproporcionado. Porque otros países han incumplido de manera más flagrante y criminal las resoluciones de la ONU (Israel, Marruecos)»; «La hipocresía de los poderosos. Actúan donde tienen intereses económicos permitiendo dictaduras donde les conviene y no les incordian".

42. Ejemplo: «Contra el Gobierno Aznar, por su seguidismo y prepotencia». 
Tabla 6. Primera razón para participar en el 15-F de acuerdo con los sectores políticos (\% de columna).

\begin{tabular}{lccccc}
\hline & PP & PSOE & IU & Abstención política & Total \\
\hline Motivos morales & $76,7^{*}$ & 58,2 & 54,0 & 51,5 & 58,2 \\
Crítica autoridades políticas & $11,6^{*}$ & 33,0 & 36,8 & 26,5 & 30,3 \\
La participación como razón & 9,3 & $6,0^{*}$ & 9,2 & $17,6^{*}$ & 9,2 \\
Otros & 2,3 & 2,7 & 0,0 & 4,4 & 2,4 \\
\hline Total & $\mathbf{1 0 0}$ & $\mathbf{1 0 0}$ & $\mathbf{1 0 0}$ & $\mathbf{1 0 0}$ & $\mathbf{1 0 0}$ \\
\hline
\end{tabular}

Casos válidos: 384

V de Cramer, 135 (Sig. aprox. 0,013).

* Variaciones de casilla significativas (por encima o por debajo de la frecuencia esperada; nivel de confianza del 95\%).

Fuente: IPPS2003-Spain.

como las que expresan opiniones antiimperialistas o anticapitalistas (4\%), así como posturas contrarias al poder militar hegemónico (4\%), son menos frecuentes. Por último, hay dos discursos que aluden a motivaciones de tipo individual, como el deseo de expresar su posición en un acto público $(6,5 \%)$ o considerarlo como una responsabilidad ciudadana $(10 \%)^{43}$.

Aunque, las diversas motivaciones suelen aparecer combinadas, se aprecian variaciones relevantes entre los cuatro sectores políticos de los asistentes a la manifestación. La tabla 6 presenta los porcentajes de las razones mencionadas en primer lugar, agrupadas en estos tres tipos: razones morales, razones de crítica política y razones que señalan la importancia de la participación $^{44}$.

Así, tal como cabría esperar, el porcentaje de votantes del PP que aluden a razones de tipo moral (la oposición a la guerra y el carácter injusto de la intervención, la existencia de víctimas inocentes, etc.) es significativamente superior. Al mismo tiempo, las motivaciones de tipo político y, en concreto, las referencias directas al Gobierno, son poco frecuentes en comparación con las expresadas por los votantes del PSOE e IU. Por su parte, los abstencionistas políticos se diferencian significativamente por señalar con más frecuencia el valor de la participación, ya sea como medio de expresar sus opiniones o como ejercicio de responsabilidad política. La relativa menor importancia de la dimensión de crítica al Gobierno entre los votantes del PP también se refleja de manera significativa en el menor porcentaje de encuestados que se muestran completamente insatisfechos con los esfuerzos realizados por el gabinete de Aznar

43. Ejemplos: «Porque creo que es lo único que puedo hacer contra la guerra»; «Para expresar activamente mi opinión»; "Necesidad de comprobar que somos capaces de unirnos a favor de un ideal»; «No quiero quedarme impasible ante una decisión tan contraria a mis principios".

44. Los resultados pormenorizados pueden verse en la tabla A.3. del anexo. 
para evitar el guerra: 70\% frente a porcentajes superiores al $90 \%$ entre los encuestados pertenecientes a los demás sectores ${ }^{45}$.

\section{Conclusiones: implicaciones electorales del 15-F}

Pese a la opinión mayoritaria contraria a la guerra de Irak, no todos los sectores sociales expresaron esta opinión en las calles. En términos sociodemográficos, los sectores con niveles de educación más bajos no están representados. Desde la perspectiva de las actitudes políticas, la afinidad partidista y el nivel de competencia política también establece un factor importante que distingue a los manifestantes del resto de la población. Una gran parte del electorado conservador y los sectores políticamente más apáticos estuvieron ausentes. Dentro de cierta homogeneidad sociopolítica de los participantes (nivel alto de estudios, interés por la política de activismo político), hemos distinguido cuatro sectores que se diferencian, fundamentalmente, en términos de actitudes y comportamientos políticos: nuevas generaciones de demócratas cristianos vinculados electoralmente al PP, sectores socialdemócratas clásicos (votantes del PSOE), «críticos politizados», cercanos a IU y, por último, el sector de abstencionistas políticos. Cada uno de estos sectores también pueden diferenciarse en cuanto a las razones subjetivas que motivan su participación. En líneas generales, las motivaciones de tipo moral son más frecuentes entre los conservadores, mientras que las razones de tipo político son relativamente más frecuentes entre los votantes de los partidos de izquierda, con un contenido ideológico más radical entre los votantes de IU. Por último, los abstencionistas políticos responden, por encima de la media, a motivaciones políticas de carácter más personal para explicar su participación.

Estos resultados sintonizan con los estudios que señalan que el proceso de normalización de la protesta es más cierto en cuanto a la mayor participación de la mujer y, con matices, la edad de los participantes, mientras que el nivel educativo se mantiene como un factor predictivo crucial. También indican que las actitudes políticas, expresadas, por ejemplo, en niveles de participación cívica o interés por la política, desempeñan un papel importante para explicar el recurso a la protesta. El perfil del manifestante como políticamente activo, votante en igual o mayor proporción que la población en general, apoya la interpretación del aumento de la contestación social como una extensión de los canales de participación en la democracia, más que como un elemento disfuncional o un síntoma de desafección democrática.

El aumento de ciudadanos contestarios es congruente con la existencia de un proceso de individualización de la política, especialmente entre un sector (creciente) de ciudadanos políticamente competentes, dispuestos a movilizarse políticamente en relación con un número creciente de temas. La presencia

45. La correlación entre sectores y esta variable es significativa con un coeficiente (V de Cramer) de 0,205 (Sig. aprox. 0,000). 
entre los manifestantes del 15-F de un sector de votantes del PP, pese a la naturaleza de oposición al Gobierno de la protesta, puede ser interpretada como un indicador de la incidencia potencial de este proceso en el debilitamiento de la identificación partidista en las decisiones de comportamiento político de los ciudadanos.

En este sentido, y a la luz de los resultados obtenidos, cabe preguntarse, por último, acerca de las consecuencias electorales del conflicto de Irak y, concretamente, en qué medida incidió en la intención de voto de los distintos sectores de participantes en el 15-F. En pocas ocasiones un tema de esta naturaleza ha estado tan presente en una campaña electoral. La guerra de Irak fue un tema central en la campaña electoral de las elecciones generales del 14 de marzo y ha desempeñado un papel fundamental en las decisiones de los electores y, a la postre, en la derrota electoral del PP. De acuerdo con la encuesta postelectoral elaborada por Demoscopia en abril de 2004, la guerra fue el segundo tema señalado con más frecuencia como el más importante de la campaña electoral, por encima de los atentados del 11- $\mathrm{M}^{46}$. En otra pregunta del mismo estudio, un $18 \%$ de los encuestados afirma que la actuación del Gobierno en el conflicto de Irak influyó mucho o bastante en su voto. En la medida en que el 15-F supuso un evento crítico en la conformación de las actitudes de los participantes (y del conjunto de la población), que consolidó el tema de la guerra en la agenda electoral e influyó en las decisiones posteriores de los votantes, nuestra encuesta ofrece una oportunidad excepcional para indagar en las consecuencias electorales de la protesta ${ }^{47}$.

La tabla 7 ofrece los resultados de la intención de voto de los manifestantes según su conducta electoral previa. Los resultados muestran como el sector de los votantes del PSOE confirmaba su voto en mayor medida que ninguna otra opción. Además, el PSOE era la fuerza política que resultaba más beneficiada por los trasvases de voto entre el resto de los sectores presentes en la manifestación. Un 31\% de los votantes del PP y un 52\% de los que no votaron (por edad o por estar de viaje) afirmaban su intención de votar al PSOE. Incluso un $17 \%$ de los votantes de IU expresaron su intención de votar al PSOE, mientras que el flujo en la dirección contraria es menor (un 6\%); es decir, ya se apunta un saldo positivo para el PSOE en la transferencia de votos entre los dos principales partidos de izquierda.

Pero, ¿en qué medida los resultados electorales de marzo de 2004 confirman estas tendencias? La tabla 8 compara las variaciones en puntos porcentuales entre la conducta electoral pasada y la intención de voto respecto a los tres principales partidos y una categoría adicional que englobaría al resto de las candidaturas, con las diferencias reales que se produjeron en las elecciones

46. En concreto, un $22,1 \%$ de los encuestados señaló el terrorismo y un $21 \%$, la guerra de Irak, mientras que, por ejemplo, el atentado del 11-M sólo es considerado como el más importante por un $8,3 \%$ de los encuestados (Demoscopia, estudio n. ${ }^{\circ} 174005$ ).

47. Para una contextualización de los resultados de las elecciones de 2004, véase Santamaría, 2004. 
Tabla 7. Intención de voto en las próximas elecciones generales de acuerdo con la conducta electoral previa.

Intención de voto

\begin{tabular}{lcccccccr}
\hline & \multicolumn{10}{c}{$\begin{array}{c}\text { Blanco/ } \\
\text { ninguno/ }\end{array}$} \\
Recuerdo voto & PP & PSOE & \multicolumn{1}{c}{ IU } & Otros & no votaría & No sabe & NC & N \\
\hline PP & 13,6 & 31,8 & 4,5 & 0,0 & 9,1 & 38,6 & 2,3 & 44 \\
PSOE & 0,0 & 88,2 & 5,9 & 1,1 & 0,0 & 4,3 & 0,5 & 186 \\
IU & 0,0 & 17,0 & 63,6 & 6,8 & 0,0 & 12,5 & 0,0 & 88 \\
Otros & 0,0 & 23,1 & 23,1 & 23,1 & 0,0 & 30,8 & 0,0 & 13 \\
Blanco / abstención política & 0,0 & 16,9 & 8,5 & 8,5 & 23,9 & 33,8 & 8,5 & 71 \\
No votó (por edad / de viaje) & 0,0 & 52,6 & 13,2 & 2,6 & 7,9 & 21,1 & 2,6 & 38 \\
\hline Total & 1,4 & 51,8 & 18,9 & 4,1 & 5,5 & 16,4 & 2,0 & 440 \\
\hline$N$ & 6 & 228 & 83 & 18 & 24 & 72 & 9 & 440 \\
\hline
\end{tabular}

Casos válidos: 440

Fuente: IPPS2003-Spain.

generales de 2000 y 2004. Como puede observarse, entre las actitudes de los manifestantes del 15-F, ya se reflejaban algunas de las tendencias de cambio de voto que condujeron a los resultados electorales de 2004.

Llama la atención que los cambios coinciden en gran medida para los casos de los partidos que cuentan con una representación amplia entre los manifes$\operatorname{tantes}^{48}$. El crecimiento del voto socialista y el estancamiento de IU están ya presentes en los resultados de la encuesta durante la manifestación del 15-F. Entre los manifestantes, el voto del PP pasó del 10\% al 1,4\%, es decir perdió 8,6 puntos. En la realidad, esa caída se redujo a 1,6 puntos. Si tenemos en cuenta la infrarrepresentación de votantes de este partido a favor de los que se sitúan en posiciones más al centro-izquierda, es posible señalar la pérdida de votos dentro de este sector específico como uno de los principales focos de trasvase de votos conservadores hacia las filas socialistas.

Consideramos que la coincidencia entre la tendencia de cambio en la orientación del voto apuntada en la encuesta entre los manifestantes y los resultados de las elecciones generales un año más tarde no es causal, sino que refleja una tendencia observable a nivel general en las encuestas de opinión. Los datos sobre intención de voto entre los manifestantes del 15-F son congruentes con

48. De nuevo, hay que tener en cuenta que la encuesta no es representativa para el ámbito estatal, dada la sobrerrepresentación de residentes en la Comunidad de Madrid, con un panorama de partidos diferente de otras zonas de España, donde se cuenta con la amplia implantación. 
Tabla 8. Comparación del cambio en el voto entre los manifestantes y los resultados de las elecciones generales de 2004. Diferencias en puntos porcentuales.

\begin{tabular}{lccrc}
\hline & PP & PSOE & IU & Otros \\
\hline Intención-recuerdo entre los manifestantes & & & & \\
(encuesta IPPS-Spain) & $-8,6$ & 9,5 & $-1,1$ & 1,1 \\
Resultados oficiales 2004-2000* & $-1,6$ & 9,1 & 0,1 & 0,3 \\
\hline
\end{tabular}

Fuente: IPPS2003-Spain y Ministerio del Interior (http://www.elecciones.mir.es/).

* Diferencias de los porcentajes relativos al conjunto de electores (y no votos válidos a candidaturas).

los arrojados en la serie temporal de sondeos de opinión del CIS, que señalaron las mejores expectativas de voto socialista precisamente en este momento, en un escenario electoral que volvería a cristalizar en las elecciones de marzo (véase Santamaría, 2004).

En este sentido, no resulta exagerado afirmar que la manifestación del 15-F significó un evento político de gran trascendencia electoral. No sólo fue una expresión de la oposición a la guerra, sino que también apunta un cambio de fondo en la posición de los españoles frente al Gobierno con consecuencias electorales que se desvelarían decisivas en el contexto de las elecciones generales. En la manifestación, estuvieron representados los sectores que, a modo de masa crítica, determinarán, con sus opciones electorales, el cambio de Gobierno en las elecciones del 14 de marzo de 2004. Tres tendencias de este cambio pueden observarse en las actitudes de los participantes en el 15-F. En primer lugar, se observa una tendencia de pérdida de apoyo entre un sector concreto de votantes del PP, que hemos descrito como jóvenes democristianos. Éstos tienden a justificar su participación en términos de motivaciones morales, que parecen ejercer un poder superior a la presión de la lealtad al Gobierno por el que votaron. De hecho, representan el sector con una mayor volatilidad en su intención de voto. En segundo lugar, la orientación de la intención del voto de los abstencionistas políticos, también sugiere un cambio importante, indicando su inclinación por el PSOE (y, en menor medida, IU). En tercer lugar, se produce un trasvase de votos entre los dos partidos de izquierdas, favorable, en términos relativos, para los socialistas.

Estos resultados sugieren que las investigaciones basadas en encuestas a los participantes en eventos de protesta no sólo contribuyen a nuestro conocimiento del comportamiento político no convencional, sino que también, en un contexto de creciente importancia electoral del voto temático y en la medida que las protestas contribuyen a la visibilidad política de los distintos temas, ofrecen un instrumento eficaz para estudiar su incidencia en el comportamiento electoral. 


\section{Anexo}

Tabla A.1. Nivel de movilización en diversos países durante la jornada internacional contra la guerra del 15-F.

\begin{tabular}{llll}
\hline & $\begin{array}{l}\text { Manifestantes } \\
\text { (en miles) }\end{array}$ & $\begin{array}{l}\text { Población } \\
\text { (en millones) }\end{array}$ & $\begin{array}{l}\text { Nivel de movilización } \\
\text { (en \%) }\end{array}$ \\
\hline Estados Unidos & 2.500 & 290,3 & 0,9 \\
Reino Unido & 1.000 & 60,1 & 1,6 \\
España & 1.500 & 40,2 & 3,7 \\
Italia & 1.500 & 58 & 2,6 \\
Holanda & 70 & 16,2 & 0,4 \\
Alemania & 500 & 82,4 & 0,6 \\
Bélgica & 72 & 10,3 & 0,7 \\
Suiza & 45 & 7,4 & 0,6 \\
\hline Total & $\mathbf{6 . 6 8 7}$ & 564,9 & 1,2 \\
\hline
\end{tabular}

Fuente: IPPS2003.

Tabla A.2. Representatividad de los participantes respecto a la población general (mayor de 14 años).

Índice

ISSP-Spain Censo 2001 de representatividad*

Sexo

Hombre

48,2

48,6

1,0

Mujer

51,8

51,4

1,0

Grupos de edad

Hasta 24 años

Entre 25 y 44 años

12,8

17,2

0,7

Entre 45 y 64 años

48,5

37,3

1,3

35,6

25,8

1,4

65 años o más

3,1

19,7

0,2

Nivel de estudios

Hasta primarios

Secundarios

$$
6,4
$$

19,0

Universitarios medios

16,8

38,4

0,2

Universitarios superiores 42,9

48,0

0,4

Postgrado

14,8
6,7

2,5

6,4

6,7

0,5

Fuente: IPPS2003-Spain y Censo 2001 (www.ine.es).

* Razón entre el porcentaje de la categoría en la muestra de manifestantes y el porcentaje en el censo de 2001. 
Tabla A.3. Razones dadas para participar en la manifestación del 15-F* según conducta electoral previa.

\begin{tabular}{|c|c|c|c|c|c|c|c|}
\hline $\begin{array}{l}\text { Razones por las que participa } \\
\text { en la manifestación }\end{array}$ & $\mathrm{PP}$ & PSOE & IU & Otros & $\begin{array}{l}\text { Blanco / } \\
\text { abstención } \\
\text { política }\end{array}$ & $\begin{array}{l}\text { No votó } \\
\text { (por edad / } \\
\text { de viaje) }\end{array}$ & Total \\
\hline Pacifismo & 39,5 & 31,3 & 35,6 & 46,2 & 36,8 & 30,6 & 34,3 \\
\hline Crítica posición del Gobierno español & 14,0 & 23,1 & 31,0 & 23,1 & 8,8 & 16,7 & 21,0 \\
\hline Desacuerdo con las razones esgrimidas & 16,3 & 23,6 & 19,5 & 7,7 & 17,6 & 25,0 & 20,7 \\
\hline Guerra injusta / doble rasero & 25,6 & 17,6 & 19,5 & 7,7 & 13,2 & 5,6 & 16,8 \\
\hline $\begin{array}{l}\text { Estilo autoritario, } \\
\text { restricciones a la democracia }\end{array}$ & 11,6 & 17,6 & 12,6 & 15,4 & 14,7 & 13,9 & 15,2 \\
\hline Ilegalidad internacional & 20,9 & 18,7 & 8,0 & 7,7 & 5,9 & 5,6 & 13,3 \\
\hline Solidaridad con iraquíes / civiles & 16,3 & 12,1 & 11,5 & 15,4 & 8,8 & 22,2 & 12,8 \\
\hline Participar / responsabilidad política & 11,6 & 6,0 & 9,2 & 15,4 & 13,2 & 22,2 & 10,0 \\
\hline Crítica al Gobierno EEUU/ Bush & 7,0 & 8,8 & 12,6 & 7,7 & 5,9 & 2,8 & 8,4 \\
\hline Testimonio personal & 2,3 & 4,9 & 4,6 & 7,7 & 14,7 & 8,3 & 6,5 \\
\hline Antiimperialismo / anticapitalismo & 0,0 & 2,2 & 9,2 & 0,0 & 5,9 & 8,3 & 4,4 \\
\hline Crítica poder mundial hegemónico & 0,0 & 4,4 & 4,6 & 15,4 & 1,5 & 5,6 & 4,0 \\
\hline \multirow[t]{2}{*}{ Otras } & 2,3 & 4,4 & 0,0 & 0,0 & 4,4 & 2,8 & 3,0 \\
\hline & 167,4 & 174,7 & 178,2 & 169,2 & 151,5 & 169,4 & 170,4 \\
\hline
\end{tabular}

Casos válidos: 440 Respuesta múltiple.

Cierre a la pregunta abierta "¿Por qué decidió participar en esta manifestación?».

Fuente: IPPS2003-Spain.

\section{Bibliografía}

Barnes, S.; KaAse, M. (eds.) (1979). Political Action. Beverly Hills, CA: Sage.

BARREIRO, B. (2004). « ¿Cuándo las desigualdades sociales se convierten en desigualdades políticas?». Zona Abierta, 106/107: 65-90.

CAÍnZOS, M.A.; GAYO CAL, M. (2003). «El perfil social y político de los participantes en las protestas con motivo de la guerra de Irak». Trabajo presentado en las II Jornadas del Comité de Investigación de Sociología Política de la FES. Madrid, 11-12 de diciembre.

CASQUeTe, J. (2003). Movimientos sociales y democracia. Cuadernos Bakeaz, núm. 55. CHRISAFIS y otros (2003). «Millions worldwide rally for peace». The Guardian unlimited (http://www.guardian.co.uk/antiwar/story).

Dalton, J.R. (1996). Citizens Politics. Chatham, NJ: Chatham House.

- (2000). «Citizens attitudes and political behaviour». Comparative Political Studies, 33(6/7): 912-940.

FaVre, P.; Fillieule, O.; MAYer, N. (1997). «La fin d'une etrange lacune de la sociologie des mobilisations: L'etude par sondage des manifestants: Fondements theoriques et solutions techniques». Revue Francaise de Science Politique, 47 (1): 3. 
FuCHS, D.; KuIngemanN, H.-D. (1995). «Citizens and the state: A relationship transformed». En: Klingemann, H.-D.; Fuchs, D. (eds.). Citizens and the state. Oxford, Reino Unido: Oxford University Press, p. 419-443.

GraEBNER, D. (2003). «10 Million worldwilde protest Bush's war» (http://www.mindfully.org/Reform/2003/Bush).

JimÉNEZ, M. (2005). El impacto político de los movimientos sociales: Un estudio de la protesta ambiental en España. Madrid: CIS-Siglo XXI. Colección Monografías, núm. 214.

Prat, E. (2003). «Los impactos del movimiento por la paz y antimilitarista de los años ochenta y noventa». Ponencia presentada en el VI Congreso de Ciencia Política y de la Administración. Barcelona, septiembre.

NORRIS, P. (1999). "Conclusions: the growth of critical citizens and its consequences». En: NORRIS, P. (ed.). Critical Citizens: Global support for democratic government. Oxford, Reino Unido: Oxford University Press, p. 257-272.

- (2002). Democratic Phoenix: Reinventing political activism. Cambridge, Reino Unido: Cambridge University Press.

Norris, P.; Walgrave, S.; Van Aelst, P. (2005). «Who demonstrates? Antistate Revels, conventional participants or Everyone?». Comparative politics, 37(2).

SANTAMARÍA, J. (2004). «El azar y el contexto: Las elecciones generales de 2004». Claves de Razón Práctica, 146: 28-40.

Topf, R. (1995). «Beyond electoral participation». En KLINGEMANN, H.-D.; FuCHS, D. (eds.). Citizens and the state. Oxford, Reino Unido: Oxford University Press, p. 52-91.

Van Aelst, P.; Walgrave, S. (2001). «Who is that (wo)man in the street? From the normalisation of protest to the normalisation of the protester». European Journal of Political Research, 39: 461-486.

VerbA, S.; NIE, N.; KIM, J. (1978). Participation and political equality: A seven-nation comparison. New York: Cambridge University Press.

Verba, S.; Schlozman, K. L.; Brady, H.; Nie, N.H. (1993). "Citizen Activity: who participates? What do they say?». American Political Science Review, 87(2): 303-318.

WALgRAVE, S.; Verhust, J. (2003). «Worldwilde anti-war-in-Iraq protest. A preliminary test of the transnational movements thesis. Outline of a research programme» (www.uia.ac.be/u/wwwm2p/IPPS/main.htm).

WalgraVe, S.; Rucht, D.; VAN AElST, P. (2007, en preparación). «Socio-demographics: Typical new social movement activists, old leftists or normalized-procesters?». En: Walgrave, S.; Rucht, D. (eds.). Global day for peace. Minneapolis: University of Minnesota Press. 